\title{
Manufactures Human Over-the-Counter Drug Products Produced Under a Monograph
}

National Cancer Institute

\section{Source}

National Cancer Institute. Manufactures Human Over-the-Counter Drug Products

Produced Under a Monograph. NCI Thesaurus. Code C131708.

The process of manufacturing non-prescription medications under a monograph (as opposed to under an approved drug application), for humans by a pharmaceutical company. 